\title{
Effect of incomplete milking during the first 5 days in milk on udder and reproductive tract health: Results from a randomized controlled trial
}

\author{
C. Krug, ${ }^{*} \dagger$ P.-A. Morin, $\ddagger$ P. Lacasse, $† \S ~ J .-P . ~ R o y, \dagger \ddagger ~ J . ~ D u b u c, \ddagger$ and S. Dufour ${ }^{*} \dagger^{1}$ \\ *Département de Pathologie et Microbiologie, \\ †Canadian Bovine Mastitis and Milk Quality Research Network, and \\ ‡Département de Sciences Cliniques, Faculté de Médecine Vétérinaire, Université de Montréal, 3200 Rue Sicotte, St-Hyacinthe, Québec, \\ J2S 2M2, Canada \\ §Sherbrooke Research and Development Centre, Agriculture and Agri-Food Canada, 2000 College, Sherbrooke, Québec, J1M 0C8, Canada
}

\begin{abstract}
The aim of this study was to investigate the effect of an incomplete milking on risk of mastitis and reproductive tract disease. Multiparous dairy cows $(\mathrm{n}=878)$ from 13 commercial herds were enrolled in a randomized controlled trial. Cows were randomly assigned to either a control (milked conventionally) or a treatment group, which consisted of an incomplete milking (10-14 L of milk collected/d) from 1 to $5 \mathrm{~d}$ in milk (DIM). Quarter milk samples were collected at approximately 11 and 18 DIM to measure somatic cell count (SCC). Quarters were considered negative for intramammary infection if SCC was $<100,000$ cells $/ \mathrm{mL}$ and positive if SCC was $\geq 200,000$ cells $/ \mathrm{mL}$. To calculate intramammary infection incidence, negative quarters of the initial samples collected were tested again $1 \mathrm{wk}$ later. This was done to deter incidence of positive quarters. To calculate elimination rate, positive quarters were tested again $1 \mathrm{wk}$ later to detect mastitis elimination. Farmers recorded clinical mastitis events. Cows were also examined at approximately 35 DIM with a Metricheck device (Simcro, Hamilton, New Zealand) for detection of purulent vaginal discharge (PVD) and with an endometrial cytobrush for presence of leukocytes [endometrial cytology for smear (ENDO) and for leukocyte esterase test (LE)]. A threshold $\geq 3$ was used to define a positive PVD or LE test, whereas a polymorphonuclear cell count $\geq 6 \%$ was used to define a positive ENDO. Five generalized mixed models with cow or herd as random intercepts were used to determine the effects of incomplete milking on odds of new intramammary infection, odds of intramammary infection elimination, and odds of a positive PVD, LE, or ENDO status. To investigate time until first clinical mastitis event, a Cox
\end{abstract}

Received March 7, 2018.

Accepted June 12, 2018.

${ }^{1}$ Corresponding author: simon.dufour@umontreal.ca model with a herd frailty term was used. The odds of new intramammary infection and intramammary infection elimination for incompletely milked cows were 0.90 [95\% confidence interval (CI): $0.49,1.7]$ and 2.9 (95\% CI: 1.4, 6.0) times those of conventionally milked cows, respectively. The hazard of clinical mastitis in incompletely milked cows was 0.96 (95\% CI: 0.59, 1.6) times that of conventionally milked cows. The odds of PVD, LE, and ENDO for incompletely milked cows were 1.4 (95\% CI: $0.89,2.1), 1.3$ (95\% CI: $0.88,1.8)$, and 1.2 (95\% CI: $0.81,1.7)$ times those of conventionally milked cows. These results suggest that incomplete milking during the first 5 DIM increases the odds of a decrease in SCC from 11 to 18 DIM but does not affect odds of increase in SCC in the same period. The incomplete milking had no effect on clinical mastitis incidence in the first 90 DIM or on reproductive tract health at 35 DIM.

Key words: dairy cow, incomplete milking, mastitis, reproductive tract disease

\section{INTRODUCTION}

Dairy cows produce a large quantity of milk very quickly after parturition, and their dietary intake in early lactation is not sufficient to meet their energy requirements, which leads to mobilization of body reserves and a negative energy balance (NEB; Bertoni et al., 2009). This is especially true for multiparous cows, which have a very steep increase in milk yield early in lactation (Wathes et al., 2007). The resulting NEB can lead to several negative metabolic and health issues in periparturient dairy cows, including increased susceptibility to infectious diseases such as mastitis (Suriyasathaporn et al., 2000; Holtenius et al., 2004) and metritis (Reist et al., 2003; Hammon et al., 2006; Huzzey et al., 2007).

Elevated blood concentrations of nonesterified fatty acids (NEFA) and ketone bodies (hyperketonemia) are commonly used indices for the presence of NEB 
because they are related to increased mobilization of fat. Several studies have shown an association between elevation of these metabolites and immunosuppression (Lacetera et al., 2005; Mulligan and Doherty, 2008; Ster et al., 2012). Nonesterified fatty acids appear to exert a direct negative effect on the immune system, but the relationship between the presence of ketone bodies and decreased immune function appears to be attributable to the link between ketone bodies and NEFA (Hegardt, 1999; Drackley et al., 2001; Ster et al., 2012). Decreasing the cow's energetic demand during the first days postpartum might improve resistance to infection by decreasing the release of NEFA into the blood circulation (Carbonneau et al., 2012; Morin et al., 2018).

Because NEB is associated with immunosuppression, we hypothesized that preventing NEB by milking dairy cows incompletely in early lactation would result in a reduction of the subsequent risk of mastitis and reproductive tract diseases. Therefore, the aim of this study was to use the large data set generated by Morin et al. (2018) and Krug et al. (2018), which was a randomized controlled trial (RCT), to evaluate the effect of incomplete milking during the first 5 DIM on mastitis and reproductive tract disease. Using the previous studies, we demonstrated that incomplete milking for the first 5 DIM leads to decreased odds of experiencing hyperketonemia through 17 DIM (Morin et al., 2018) without subsequent effects on milk yield and composition throughout the lactation (Krug et al., 2018). Our specific objectives for the current study were to measure, on that same population of cows, the effects of incomplete milking on (1) incidence of IMI, (2) IMI elimination rate, (3) time until first clinical mastitis event, (4) incidence risk of clinical mastitis in the first
90 DIM, (5) prevalence of purulent vaginal discharge (PVD), (6) prevalence of cytological endometritis (ENDO), and (7) prevalence of leukocyte esterase endometritis (LE).

\section{MATERIALS AND METHODS}

\section{Sample Size Calculations}

The original study was designed to investigate the effect of incomplete milking on ketonemia and odds of hyperketonemia (Morin et al., 2018), odds of infectious diseases, fertility, culling hazard, and milk production (Krug et al., 2018). Sample size calculation was computed for all of these different outcomes. Odds of hyperketonemia was the outcome requiring the largest sample size (no./group $=400)$, and therefore it determined the number of animals used in the RCT described in this study. Nevertheless, using the POWER procedure in SAS 9.4 (SAS Institute Inc., Cary, NC), we determined the minimal differences that could be detected for each of the outcomes examined in this experiment. For these calculations, we used the predetermined sample size of 400 animals per group, a 95\% confidence level, $80 \%$ power, and various udder health and reproductive tract health parameters provided by the previously published literature (see Table 1). Moreover, we used the package epiR 0.9-93 (Stevenson et al., 2012) from RStudio 1.1.383 (R Core Team, 2013) to compute sample size and power calculations for time to clinical mastitis (survival analysis). Results from the sample size and power calculations are presented in Table 1. The minimal detectable clinical mastitis hazard ratio that could be detected between groups was estimated at 1.2.

Table 1. Sample size and power calculations for evaluating the effect of an incomplete milking during the first 5 DIM on udder and reproductive tract health using a $95 \%$ confidence level and $80 \%$ power

\begin{tabular}{llll}
\hline Outcome of interest & No./group & $\begin{array}{l}\text { Expected prevalence or incidence } \\
\text { in control animals (\%) }\end{array}$ & $\begin{array}{l}\text { Minimal detectable difference } \\
\text { between groups (\% points) }\end{array}$ \\
\hline $\begin{array}{lll}\text { Udder health } \\
\text { New IMI }\end{array}$ & 1,440 quarters $^{1}$ & $\begin{array}{l}3.5 / \text { quarter-week (Dufour and Dohoo, } \\
2013)\end{array}$ & \pm 1.7 \\
IMI elimination & 160 quarters $^{2}$ & $15,30,50^{3}$ & $\pm 14, \pm 16, \pm 16$ \\
$\begin{array}{l}\text { Reproductive tract health } \\
\text { Purulent vaginal discharge }\end{array}$ & 400 cows & 15 (Dubuc et al., 2010a) & \pm 6.5 \\
$\begin{array}{l}\text { Leukocyte esterase test } \\
\text { Endometrial cytology }\end{array}$ & 400 cows & 10 (Denis-Robichaud, 2013) & \pm 5.5 \\
\hline
\end{tabular}

${ }^{1}$ According to the Canadian Bovine Mastitis and Milk Quality Research Network (St-Hyacinthe, QC, Canada; Simon Dufour, personal communication), $10 \%$ out of 3,000 quarter-milk samples had $\geq 200,000$ cells $/ \mathrm{mL}$ at wk 2 after calving. Therefore, we would expect to have 1,440 quarters at risk of new IMI out of a total of 1,600 (4 quarters $\times 400$ cows).

${ }^{2}$ For the same reasons mentioned in footnote 1 , we would expect to have 160 quarters at risk of IMI elimination out of a total of 1,600 (4 quarters $\times 400$ cows).

${ }^{3}$ We did not find references on IMI elimination rates. Therefore, we reported minimal detectable differences for 3 different scenarios. 


\section{Herds, Animals, and Experimental Design}

This study was an RCT conducted on 13 commercial dairy farms selected by convenience. There were several requirements for selection of farms: proximity to Saint-Hyacinthe (QC, Canada), agreeing to follow the research protocol, participating in a DHIA program, having computerized health records, having a milking system that allows measurement of milk collected in real time, and agreeing to share herd health and DHIA information with the research team. The study protocol was approved by the Animal Ethics Committee of the Université de Montréal (Rech-1701). The complete research protocol is described in more detail in Morin et al. (2018).

Briefly, 1 mo before expected calving, all multiparous cows from participating farms were randomly allocated to a control or a treatment group using a random number generator. Cows in the control group were milked conventionally according to regular farm practices. On 6 farms, producers reported that they milked cows incompletely during the first 2 DIM as part of their conventional milking procedures. The treatment consists of limiting milking to a maximum of 10,12 , and $14 \mathrm{~L} / \mathrm{d}$ on DIM 1 to 3, 4, and 5, respectively, without altering milking frequency (i.e., the maximum amount allowed per day was divided by milking frequency). In one herd with an automatic milking system (AMS), cows were milked manually twice a day during the first 5 DIM and then were sent to the AMS. The milk volume thresholds for incompletely milked cows were adapted from the study of Carbonneau et al. (2012). Dairy producers were not blinded to group allocation because they were the ones applying the treatment protocol.

\section{Samples and Animal Measurements}

Udder Health. The effect of incomplete milking on udder health was investigated using 3 outcomes: IMI incidence, IMI elimination, and clinical mastitis. To evaluate IMI incidence and elimination, quarter-milk samples were collected, after fore-stripping the quarters, around 2 to $8 \mathrm{~h}$ after morning milking on [mean (standard deviation)] 11.5 (2.3) and 18.5 (2.2) DIM, respectively. Samples were analyzed by Valacta (SteAnne-de-Bellevue, QC, Canada) using the Fossomatic cell counter (Fossomatic 4000 series; Foss Electric A/S, Hillerød, Denmark) to determine the SCC of quartermilk samples. To calculate IMI incidence, only quarters without IMI (defined as having an SCC $<100,000$ cells/ $\mathrm{mL}$ ) at first sampling were considered at risk of acquiring an IMI. These were monitored again 1 wk later to detect quarters that developed an IMI (defined as SCC $\geq 200,000$ cells $/ \mathrm{mL}$ ). To calculate elimination rate, only quarters with an IMI (defined as SCC $\geq 200,000$ cells $/ \mathrm{mL}$ ) at first sampling were considered at risk of eliminating an IMI and thus were monitored again on second measurement to observe whether that IMI was eliminated (defined as SCC $<100,000$ cells $/ \mathrm{mL}$ ). These thresholds were used based on Schepers et al. (1997) and Dohoo and Leslie (1991). We therefore obtained binary outcomes for development and elimination of IMI.

Cases of clinical mastitis were recorded by participating producers in their electronic health records. A clinical mastitis case definition was presented to participating producers before the start of the study. Clinical mastitis was defined as the presence of abnormal milk or typical inflammation signs (swelling, redness, pain) of the mammary gland (Reyher et al., 2011). Weekly farm visits were conducted over the course of the study by the research team for sample collection and to ensure proper recording of clinical mastitis events by producers.

Reproductive Tract Health. On [mean (SD)] 32.9 (2.9) DIM, cows enrolled in the RCT were tested for PVD, LE, and ENDO. The Metricheck test (Simcro, Hamilton, New Zealand) was used for clinical examination of cows and resulted in a score from 0 to 5 depending on the appearance of the vaginal secretion $(0=$ no discharge; 1 = clear mucus; $2=$ mucus with flecks of pus; $3=$ mucopurulent discharge; $4=$ purulent discharge; 5 = foul-smelling discharge; McDougall et al., 2007). Positive PVD was considered when scores $\geq 3$ were observed (Dubuc et al., 2010a).

Cows were also examined using an endometrial cytology with cytobrush (VWR CanLab, Mississauga, ON, Canada) as described by Kasimanickam et al. (2004). A stainless steel instrument for endometrial cytology was sterilized before each use, and the cytobrush was threaded onto the solid steel rod and placed in the steel tube. Before examination, the instrument was placed in a sanitary plastic sleeve that was then lubricated. The vulva was cleaned using a paper towel, and the instrument was guided from the vagina to the external cervical using rectal palpation. The sanitary sleeve was punctured before entering the cervix; then the cytobrush was exposed for sampling against the uterine wall and was again placed in the steel tube before being removed from the cervix. The cytobrush was then rolled on a microscope slide to create a smear for PMN cell count and then was immediately plunged into a $3-\mathrm{mL}$ vial with $1 \mathrm{~mL}$ of $0.9 \%$ saline $(\mathrm{NaCl} 0.9 \%)$ to perform the LE test (Multistix 10 SG; Bayer Corp., Elkart, IN). 
Endometrial cytology slides were stained with modified Wright-Giemsa stain (Protocol-Hema3; Biochemical Sciences Inc., Swedesboro, NJ). Slides were then examined independently by 2 observers using a microscope at $400 \times$ magnification to count the number of PMN within 100 cells in 2 different locations of the slide. If the PMN count was between 1 and $49 \%$ in at least 1 of the slide locations, 2 more places within the same slide were examined. Two observers that were blinded to treatment group and to on-farm examination findings conducted microscopic evaluations independently. The average number of PMN within 100 cells for each slide and for each observer was calculated. If PMN was $>30 \%$ for both observers, the mean between both observers was calculated to be used as the final measurement. If the average PMN obtained was between 0 and $30 \%$ for at least 1 of the observers and differed by $>10$ percentage points between observers, a third reading was performed by a third observer and a final PMN average was calculated between the 2 most similar results. Finally, if the final PMN average was $<6 \%$, the cow was considered negative for ENDO, and if the final PMN was $\geq 6 \%$, the cow was considered positive for ENDO (Denis-Robichaud and Dubuc, 2015).

The LE test was performed with a colorimetric semiquantitative strip (Multistix 10 SG, Bayer Corp.) that changes color in the presence of leukocytes. Because darker colors are correlated with higher levels of leukocytes, interpretation of this test was as follows: $0=$ negative; $0.5=$ trace of leukocytes; $1=$ small amount of leukocytes; 2 = moderate amount of leukocytes; $3=$ large amount of leukocytes (Couto et al., 2013). A score of 3 was considered positive for the LE test (Cheong et al., 2012).

\section{Data Management and Statistical Analyses}

The experimental unit was cow for all experiments. The observational unit and the unit of statistical analysis was cow in all outcomes except for IMI outcomes, when observational unit and the unit of statistical analysis was quarter within cow.

Udder Health. The effects of incomplete milking on the odds of acquiring an IMI and the odds of eliminating an existing IMI were determined using generalized mixed models. The GLIMMIX procedure was used in SAS 9.4 (SAS Institute Inc.) to run these models. Cow and herd were considered as random intercepts to account for the higher correlation among quarter-milk samples from the same cow and among cows from the same herd. Treatment group was forced as the main predictor in the models. The general model was the following:

$$
\begin{gathered}
\mathrm{Y}_{\mathrm{ijk}} \sim \operatorname{bin}\left[P\left(\mathrm{Y}_{\mathrm{ijk}}\right)\right] \\
\operatorname{Logit}\left[P\left(\mathrm{Y}_{\mathrm{ijk}}\right)\right]=\beta_{0}+\beta_{1} \operatorname{TxGroup~}_{\mathrm{jk}} \\
+\mathrm{v}_{0 \mathrm{k}}+\mathrm{u}_{0 \mathrm{jk}}+\mathrm{e}_{0 \mathrm{ijk}},
\end{gathered}
$$

where $P\left(\mathrm{Y}_{\mathrm{ijk}}\right)$ is the probability of new IMI or of IMI elimination for the ith quarter from the jth cow from the kth herd. It is a function of treatment group (TxGroup) through the logit function, and it approximately follows a binomial distribution; $\beta_{0}$ is the intercept; $\beta_{1}$ is the regression coefficient for treatment group (conventionally vs. incompletely milked); and $\mathrm{v}_{0 \mathrm{k}}, \mathrm{u}_{0 \mathrm{jk}}$, and $\mathrm{e}_{0 \mathrm{ijk}}$ are the herd, cow, and quarter error terms, respectively (random parts of the model).

Parity (categorized as parity 2 and parity $\geq 3$ ) was tested as effect modifier of the relationship between treatment group and odds of IMI or of IMI elimination by adding the main terms and a 2 -way interaction term (treatment group $\times$ parity) in the model. Parity was retained as an effect modifier if the 2-way interaction term yielded a $P$-value $<0.05$ on the $F$-test.

Residuals were visually examined for each model to evaluate normality using quantile-quantile plot of residuals. Assumption of homoscedasticity was assessed visually using plot of the residuals against predicted values.

To investigate time until first clinical mastitis case, a Cox proportional hazard model with a herd frailty term to account for the data structure was used (PHREG procedure in SAS; SAS Institute Inc.). Time until clinical mastitis was defined as the number of days from calving until the cow developed clinical mastitis or until the cow was culled (left the herd or died). Cows were followed until 90 DIM (right censoring) or culling (whichever comes first), as we did not expect an effect of treatment in later stages of lactation. The general model was as follows:

$$
\mathrm{h}_{\mathrm{i}}(\mathrm{t})=\lambda_{0}(\mathrm{t}) \exp \left(\beta_{1} \mathrm{Tx}_{\mathrm{ij}}\right)+\varepsilon_{\mathrm{i}}
$$

where $h_{i}(t)$ is the clinical mastitis hazard for the ith cow at time $t ; \lambda_{0}(t)$ is the baseline hazard function; $\beta_{1}$ is the coefficient for the treatment group $\left(\mathrm{Tx}_{\mathrm{ij}}\right.$; conventional vs. incomplete milking); and $\varepsilon_{\mathrm{i}}$ represents the unobserved heterogeneity, accounting for difference between herds. Using this model, the clinical mastitis hazard ratio between conventionally and incompletely milked cows can be computed by exponentiation of $\beta_{1}$ using the natural base logarithmic transformation.

We also hypothesized that the relationship between treatment and clinical mastitis hazard could change by parity level; therefore, the interaction between treatment group and parity level was again tested. The 2 -way 
interaction term was kept in the model if it yielded a $P$-value $<0.05$. To evaluate whether the treatment effect varied as a function of time (i.e., the proportional hazard assumption), the log-cumulative hazard plot for incompletely and conventionally milked cows was visually inspected. The assumption of independent censoring was checked as described by Dohoo et al. (2009). Kaplan-Meier survival curves for each treatment group were produced using STATA/MP 12.0 (StataCorp, College Station, TX).

Reproductive Tract Health. Three generalized mixed models using herd as random intercept were used to study the effect of incomplete milking on the odds of a positive PVD, LE, and ENDO test. The general model was as follows:

$$
\begin{gathered}
\mathrm{Y}_{\mathrm{ij}} \sim \operatorname{bin}\left[P\left(\mathrm{Y}_{\mathrm{ij}}\right)\right] \\
\operatorname{Logit}\left[P\left(\mathrm{Y}_{\mathrm{ij}}\right)\right]=\beta_{0 \mathrm{ij}}+\beta_{1} \operatorname{TxGroup}_{\mathrm{ij}}+\mathrm{u}_{0 \mathrm{j}}+\mathrm{e}_{0 \mathrm{ij}}, \quad[3]
\end{gathered}
$$

where $P\left(\mathrm{Y}_{\mathrm{ij}}\right)$ is the probability of PVD, LE, or ENDO for the ith cow from the jth herd. It is a function of treatment group (TxGroup) through the logit function and approximately follows a binomial distribution; $\beta_{0}$ is the intercept; $\beta_{1}$ is the regression coefficient for the treatment group (conventionally vs. incompletely milked); and $\mathrm{u}_{0 \mathrm{j}}$ and $\mathrm{e}_{0 \mathrm{ij}}$ are the herd and cow error terms, respectively (random parts of the model).

Similar to IMI, parity (categorized as parity 2 and parity $\geq 3$ ) was tested as effect modifier of the relationship between treatment group and odds of PVD, LE, or ENDO by adding the main terms and a 2-way interaction term (treatment group $\times$ parity) in the model. Interaction terms were retained if the 2-way interaction term yielded a $P$-value $<0.05$ on the $F$-test. Normality and homoscedasticity were assessed as described for IMI.

\section{Adjustment for Misclassification Bias}

In the current study, quarter SCC was used to define the quarter IMI status. However, SCC accuracy for diagnosing IMI status is far from perfect. Similarly, using PVD, LE, or ENDO to define reproductive tract health status is associated with a certain level of outcome misclassification. Using these imperfect measurements could lead to biased measures of association between incomplete milking and diseases (Dufour et al., 2012; Dohoo, 2014). To correct our estimates of association for this systematic error, the sensitivity and specificity (i.e., bias parameters) of the diagnostic test used for each outcome were obtained through either external or internal data sources. Then, the method proposed by
Lash et al. (2009a,b) was used to compute the measure of association adjusted for misclassification bias.

Udder Health Bias Adjustment. To correct the odds ratio obtained with the generalized mixed models, the sensitivity and specificity of the different SCC thresholds to exclude or detect IMI were obtained through the literature (i.e., external data source). The threshold of 100,000 cells/mL of milk to define absence of IMI at the quarter level was reported to have a sensitivity of 0.81 and a specificity of 0.83 , whereas the threshold of 200,000 cells/mL of milk to detect IMI was reported to have a sensitivity of 0.75 and a specificity of 0.90 (Schepers et al., 1997).

Reproductive Tract Health Bias Adjustment. The studies conducted on the validity of diagnostic tests for reproductive tract health generally estimate validity in diagnosing future reproductive performances as opposed to estimating validity in diagnosing current reproductive tract health status (LeBlanc et al., 2002; Dubuc et al., 2010b). To compute estimates of sensitivity and specificity of these tests for diagnosing current reproductive tract health status, we used a Bayesian latent class model for 3 tests (PVD, LE, and ENDO) and 1 population as described by Branscum et al. (2005). The model was run using the MCMC procedure of SAS (SAS Institute Inc.), with uniform $\beta$ prior distributions for all parameters (sensitivity and specificity of all tests) and for prevalence of reproductive tract disease. We then used median sensitivity and specificity estimates of each test to adjust the odds ratio of each of the 3 models.

\section{RESULTS}

\section{Description of Study Population}

The herds enrolled in this project had a mean (SD) number of 103 (51) lactating cows and a mean (SD) $305-\mathrm{d}$ milk yield of 9,973 (660) kg/cow. Cows were predominantly housed in freestall barns (9/13 herds) and were milked twice a day (11/13 herds). Cows from 1 herd were milked 3 times a day, and in another herd an AMS was used. The majority of herds fed TMR (11/13 herds) and used monensin supplementation (11/13 herds). Cows from the control group produced a mean (SD) of 6.0 (3.3), 20.9 (9.9), 25.9 (8.9), 28.8 (7.9), and 30.1 (9.1) L of milk/d on DIM 1, 2, 3, 4, and 5 , respectively. The flow of quarters and cows in the current RCT is illustrated in Figure 1.

\section{Udder Health}

From a total of 3,291 sampled quarters from 847 animals, $9 \%(301 / 3,291)$ were sampled only once and 
therefore were not used in the IMI incidence and elimination analyses. Consequently, 2 successive quartermilk samples from 2,990 (1,511 conventionally milked and 1,479 incompletely milked) quarters pertaining to 779 cows were available for the udder health analyses. The mean number of sampled quarters per cow was 3.8 (range: 1-4; Table 2). Among these double- sampled quarters, $3 \%(102 / 2,990)$ had an SCC between 100,000 and 200,000 cells $/ \mathrm{mL}$ on the first sample and therefore did not met the case definitions for healthy $(<100,000$ cells $/ \mathrm{mL})$ or infected $(>200,000$ cells $/ \mathrm{mL})$. Consequently, these quarters were not considered for the IMI incidence and elimination analyses. At the first sampling, 2,735 quarters (1,387 conventionally milked

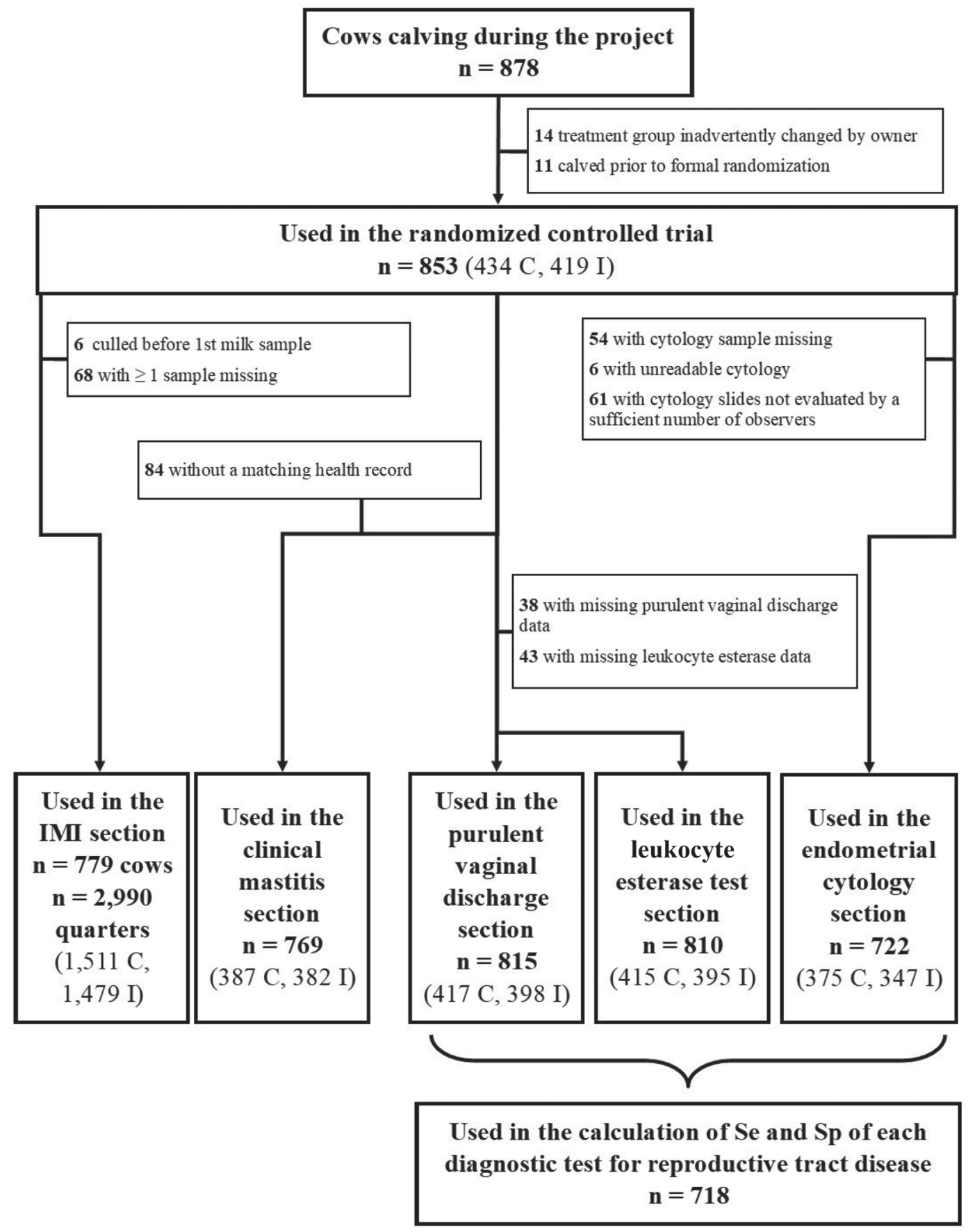

Figure 1. Flow of cows in a randomized controlled trial conducted on 13 commercial dairies evaluating the effect of incomplete milking during the first 5 DIM (I) compared with conventional milking (C) on udder and reproductive tract health. Se = sensitivity; Sp = specificity. 
Table 2. Structure of the data set for evaluating the effect of an incomplete milking during the first 5 DIM on IMI incidence and elimination $^{1}$

\begin{tabular}{|c|c|c|c|}
\hline \multirow[b]{2}{*}{ Level } & \multirow{2}{*}{$\begin{array}{l}\text { No. of } \\
\text { units }\end{array}$} & \multicolumn{2}{|c|}{$\begin{array}{c}\text { No. of } \\
\text { observations/cluster }^{2}\end{array}$} \\
\hline & & Mean & Range \\
\hline Farm & 13 & - & - \\
\hline Cow & 779 & 59.9 & $15-143$ \\
\hline Quarter & 2,990 & 3.8 & $1-4$ \\
\hline
\end{tabular}

and 1,348 incompletely milked) were free from IMI and therefore at risk of acquiring a new IMI (Table 3). New IMI rates of 1.7 and $1.5 \%$ were observed in conventionally and incompletely milked groups, respectively. The odds of new IMI for incompletely milked cows were 0.90 (95\% CI: $0.49,1.7 ; P=0.70)$ times those of conventionally milked cows. Therefore, the effect of incomplete milking on new IMI was nonsignificant. Regarding IMI elimination, 153 quarters (81 conventionally milked and 72 incompletely milked) were considered infected on first sampling (Table 3). Intramammary infection elimination rates of 24.7 and $44.4 \%$ were observed in conventionally and incompletely milked groups, respectively. Odds of IMI elimination for incompletely milked cows were 2.9 (95\% CI: 1.4, 6.0; $P<0.01$ ) times those of conventionally milked cows.

A total of 769 cows ( 387 conventionally milked and 382 incompletely milked) could be used for clinical mastitis analysis. The mean number of cows included per farm was 59 (range: 16-153). The hazard of clinical mastitis in incompletely milked cows was 0.96 (95\% CI: 0.59, 1.6; $P=0.88$ ) times that of conventionally milked cows. Kaplan-Meier survival curves of conventionally milked cows and incompletely milked cows are illustrated in Figure 2. Because curves of the log-cumulative hazard plot for incompletely and conventionally milked cows were approximately parallel, we concluded that the effect of treatment on clinical mastitis hazard did not vary as a function of time (i.e., the proportional hazard assumption was respected). The effect of treatment on clinical mastitis hazard did not vary across parity $(P$ $=0.30)$. Table 4 shows clinical mastitis incidence risk per herd along with other herd characteristics, such as mean herd SCC.

\section{Reproductive Tract Health}

The odds of PVD, LE, and ENDO for incompletely milked cows were, respectively, 1.4 (95\% CI: 0.89, 2.1;

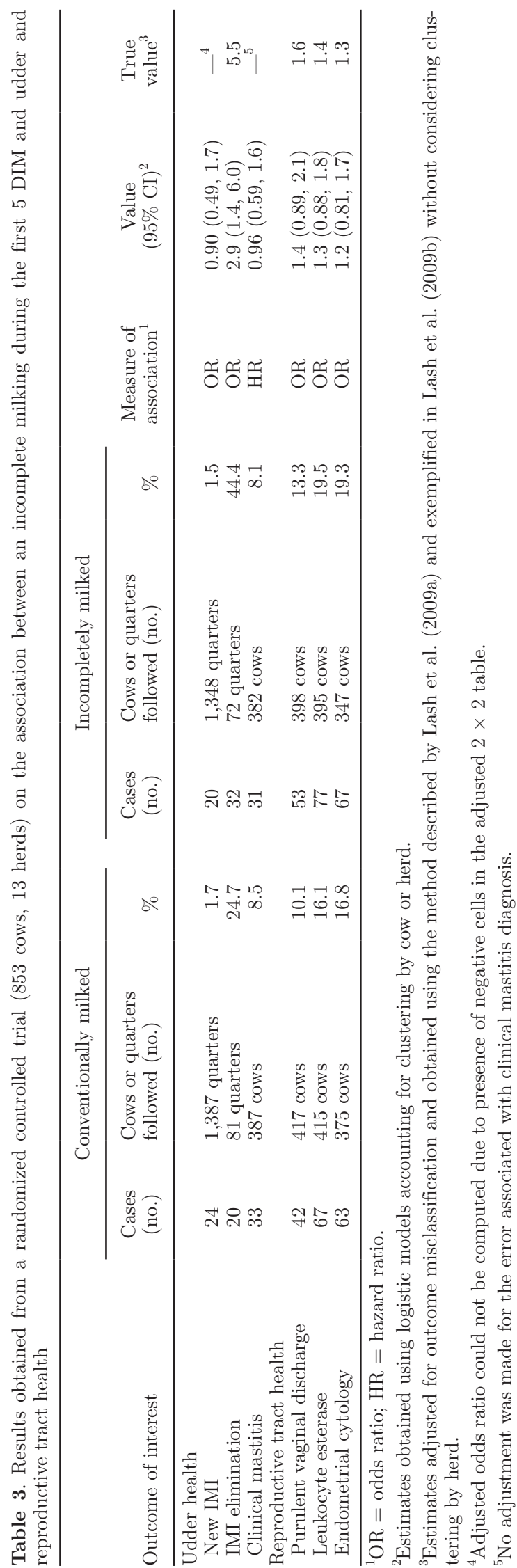

Journal of Dairy Science Vol. 101 No. 10, 2018 
$P=0.15), 1.3$ (95\% CI: $0.88,1.8 ; P=0.20)$, and 1.2 (95\% CI: $0.81,1.7 ; P=0.38)$ times those of conventionally milked cows. The effect of treatment on PVD, LE, and ENDO did not vary across parity $(P=0.27,0.07$, and 0.65 , respectively).

\section{Adjustment for Misclassification Bias}

The sensitivity and specificity found in the literature for IMI definition using the specified SCC thresholds were used to adjust the odds ratio obtained with Equation 1 for misclassification bias. The adjusted odds ratios for new IMI and for IMI elimination are presented in Table 3. Briefly, a bias-adjusted odds ratio could not be computed for IMI incidence due to the presence of negative count in some cells of the adjusted $2 \times 2$ table. For IMI elimination, the true odds ratio (5.5) was greater than the unadjusted odds ratio (2.9), indicating that the misclassification bias caused a bias toward the null value. The cross-classified test results used in the Bayesian latent class model to compute estimates of sensitivity and specificity for each reproductive tract health test (PVD, LE, and ENDO) are presented in Table 5 .
The posterior means and $95 \%$ probability intervals for the sensitivity and specificity of PVD, LE, and ENDO are presented in Table 6. True reproductive tract disease prevalence was estimated at $15 \%(95 \%$ CI: 12, 18). All 3 diagnostic tests appeared to have very good specificity $(0.97,0.95$, and 0.94 for PVD, LE, and ENDO, respectively), but the sensitivity of PVD (0.57) was lower than that of LE (0.89) and ENDO (0.89). The (misclassification) adjusted odds ratio for all 3 tests computed using the sensitivity and specificity estimates is presented in Table 3 . In this case, the adjusted and unadjusted odds ratios were similar, indicating a rather small effect of misclassification bias for the reproductive tract disorder outcomes.

\section{DISCUSSION}

In a previous article (Morin et al., 2018), we demonstrated that the incompletely milked cows enrolled in the current RCT had lower odds for hyperketonemia compared with conventionally milked animals. Assuming that the treatment protocol was applied as indicated, on the first DIM there was no additional residual milk for most cows from the treatment group compared

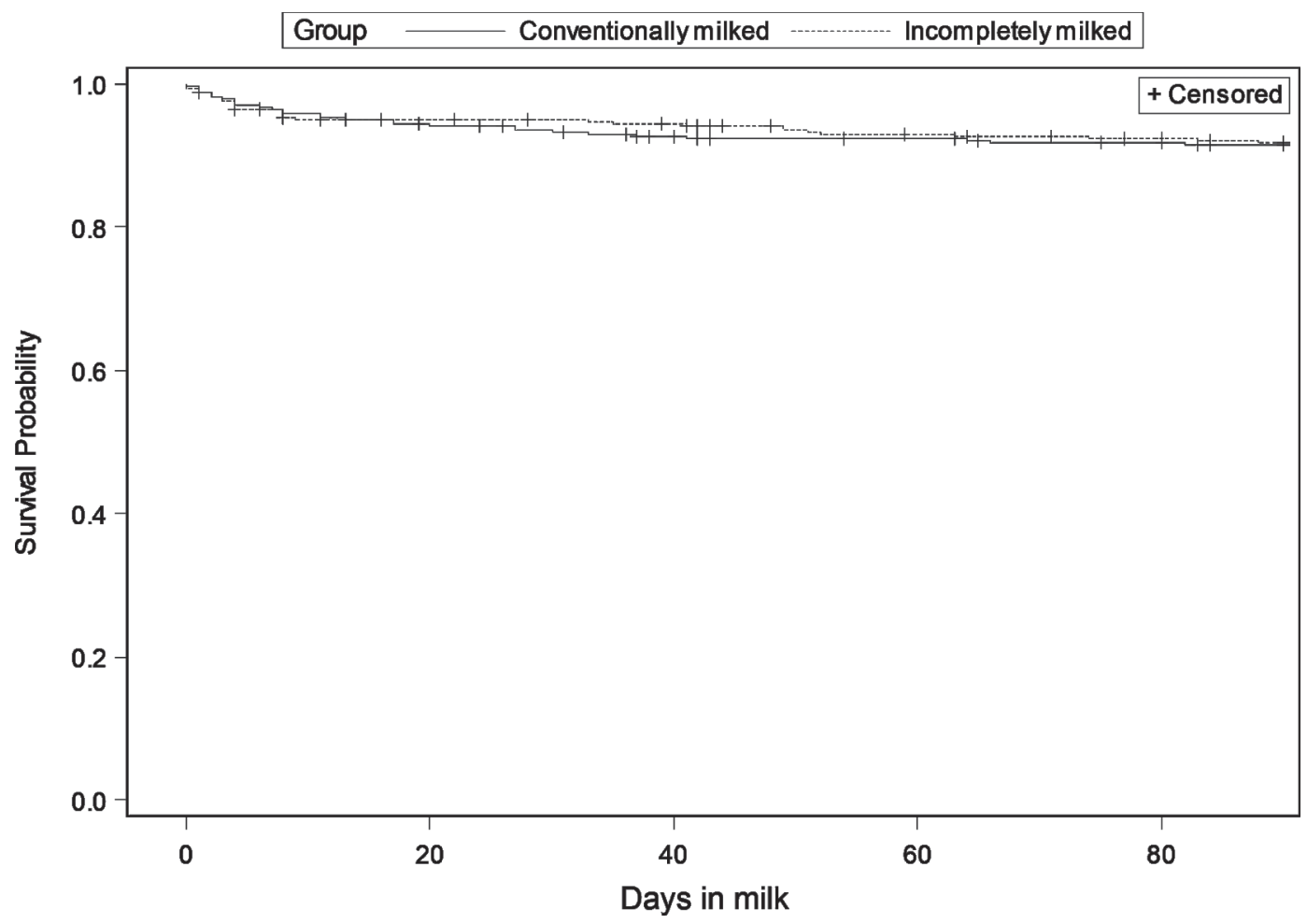

Figure 2. Kaplan-Meier survival curves illustrating clinical mastitis hazard for 769 multiparous cows from 13 commercial herds enrolled in a randomized controlled trial comparing conventionally and incompletely milked cows. 


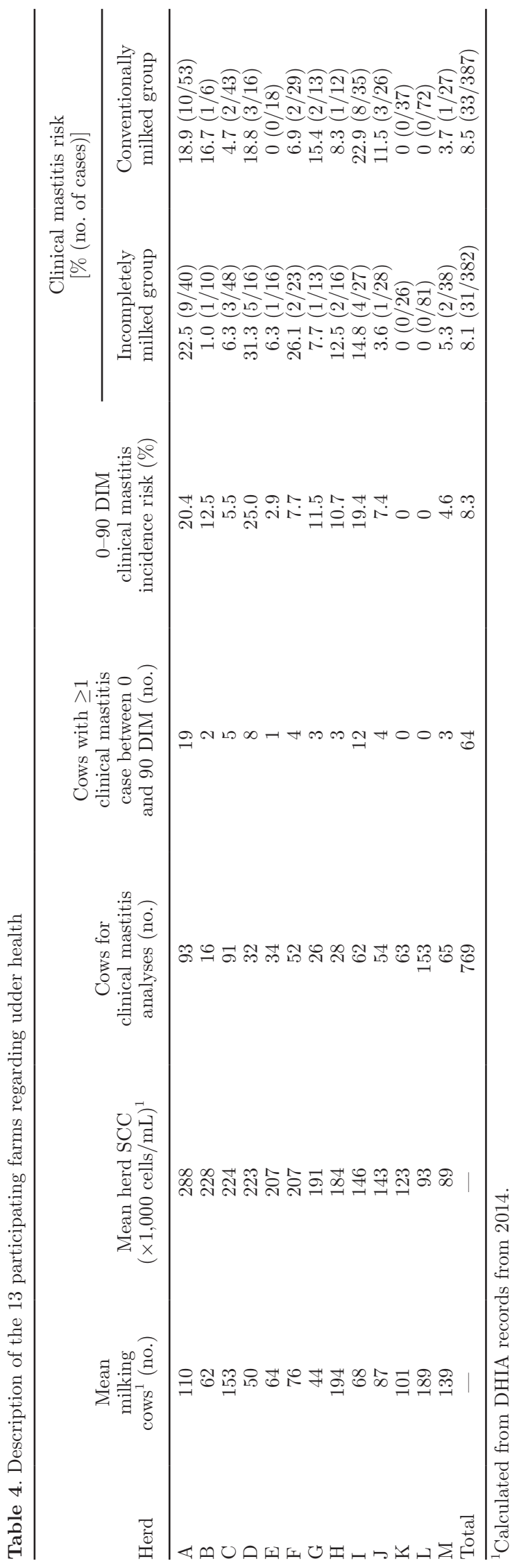

with conventionally milked cows. On DIM 2, 3, 4, and 5 , the level of uncollected milk in the incompletely milked cows corresponded to $52,61,58$, and $53 \%$ of the milk collected in the conventional group, respectively. Although energy balance was only indirectly measured in the cows enrolled in the current RCT (through BHB measurement; Morin et al., 2018), it is reasonable to assume that energy balance was improved in incompletely milked cows.

Our results on IMI elimination support the idea that incomplete milking has a positive effect on the immune system, probably through its action on limiting NEB and therefore decreasing NEFA blood concentration. Accordingly, Carbonneau et al. (2012) demonstrated that 16 cows that were submitted to an incomplete milking protocol with a residual milk of $57,65,66,62$, and $64 \%$ on $1,2,3,4$, and 5 DIM had a lower mean SCC $(43,000$ cells $/ \mathrm{mL})$ than 15 control cows $(190,000$ cells/mL) during wk 2 to 9 after calving. On the other hand, the study from Penry et al. (2017) conducted in 12 dairy cows showed that incompletely milking a halfudder from 5 to 47 DIM led to around $30 \%$ residual milk and to an increased mean SCC $(48,300$ cells $/ \mathrm{mL})$ compared with control half-udders $(26,300$ cells $/ \mathrm{mL})$. However, we believe that these differences are very small considering the range of SCC that can be observed in the mammary gland. Nevertheless, differences between the study of Penry et al. (2017) and that of Carbonneau et al. (2012) are probably a result of the different treatment lengths, different moments in lactation, and central versus local (half-udder) response.

Our results did not show an effect of incomplete milking on preventing new IMI, which might have been due to the very low IMI incidence among the cows followed $(1.6 \%)$. With such a low incidence, it is very difficult to have enough statistical power to conclude a significant effect of treatment.

Although the literature on incomplete milking as a management strategy to prevent mastitis is very scarce, many studies investigated the effect of automatic teat cup remover settings on residual milk and udder health. For example, some studies (Rasmussen, 1993; Clarke et al., 2008; Hultén, 2016) reported no differences in SCC of cows with different take-off levels (i.e., milk flow rate threshold that leads to the detachment of the milking unit), but one study reported increased SCC in cows milked with higher take-off levels (Jago et al., 2010). Effects on clinical mastitis were also nonsignificant in most studies (Rasmussen, 1993; Jago et al., 2010). The hypothesis present in most of these studies was that higher take-off levels could lead to increased residual milking and therefore an increased risk for IMI and clinical mastitis. The studies investigating residual milk (Clarke et al., 2008; Jago et al., 2010; Hultén, 2016) did 
Table 5. Cross-classified test results for reproductive tract health from purulent vaginal discharge (PVD), leukocyte esterase test (LE), and endometrial cytology (ENDO)

\begin{tabular}{lccccc}
\hline & \multicolumn{2}{c}{ ENDO positive } & & \multicolumn{2}{c}{ ENDO negative } \\
\cline { 2 - 3 } \cline { 5 - 6 } LE status & PVD positive & PVD negative & & PVD positive & PVD negative \\
\hline Positive & 49 & 37 & & 6 & 34 \\
Negative & 6 & 36 & & 17 & 533 \\
\hline
\end{tabular}

not find any differences in the volume of milk remaining in the udder in cows milked with high versus low take-off levels. Although these studies can be of interest for the topic of incomplete milking, we believe that the quantities of milk remaining in the udder in the current $\mathrm{RCT}$, although not directly quantified, were probably considerably higher.

Clinical mastitis was the only outcome that was obtained through farmers' records. Although we encouraged farmers to record cases of clinical mastitis by visiting them on a weekly basis during the study period, clinical mastitis incidence might have been underestimated in the current study. Moreover, each farmer was provided with a clinical mastitis case definition, but there was no validation of the actual application of that definition by each farmer. Differences in management strategies, bacterial populations, and case definitions might have led to the high discrepancy observed in clinical mastitis incidence risk between farms.

As mentioned earlier in this article, we hypothesized that the positive effects of incomplete milking on energy balance and NEFA, deduced from the decrease in BHB (Carbonneau et al., 2012; Morin et al., 2018), could reduce the odds of reproductive tract disease. However, the current study does not support that hypothesis. It is possible that metabolic disturbances occurring before calving are more determinant than those occurring after calving, as suggested by Hammon

Table 6. Mean and 95\% credibility interval for the sensitivity and specificity of 3 tests for detection of reproductive tract disease in dairy cows, obtained using a Bayesian latent class model comparing 3 tests in 1 population

\begin{tabular}{lcc}
\hline & & $\begin{array}{c}95 \% \\
\text { credibility } \\
\text { interval }\end{array}$ \\
Item & Mean & \\
\hline $\begin{array}{l}\text { Purulent vaginal discharge } \\
\text { Sensitivity }\end{array}$ & 0.57 & $0.47,0.68$ \\
$\quad$ Specificity & 0.97 & $0.95,0.98$ \\
$\quad$ Leukocyte esterase test & & \\
$\quad$ Sensitivity & 0.89 & $0.79,0.97$ \\
$\quad$ Specificity & 0.95 & $0.92,0.97$ \\
$\quad$ Endometrial cytology & & \\
$\quad$ Sensitivity & 0.89 & $0.79,0.97$ \\
$\quad$ Specificity & 0.94 & $0.92,0.96$ \\
Reproductive tract disease prevalence & 0.15 & $0.12,0.18$ \\
\hline
\end{tabular}

et al. (2006). An additional factor could be the time at which reproductive tract health diagnosis was evaluated. Sheldon et al. (2006) and Huzzey et al. (2007) detected a relationship between hyperketonemia and development of reproductive tract disease diagnosed at 21 to 28 DIM and <15 DIM, respectively. However, Kaufmann (2010) used the time from 28 to 35 DIM for reproductive tract health diagnosis, which is similar to the time used in the current study, and did not find an association between hyperketonemia and reproductive tract disease. With the current study design, we could not demonstrate an effect of the milking protocol on the development of reproductive tract disease earlier in lactation (0-28 DIM). This hypothesis could be investigated in future research. The lack of a positive effect of incomplete milking on reproductive tract diseases in wk 5 after calving could also be explained by a greater time lag between the actual treatment (1-5 DIM), its effects (lowering odds of hyperketonemia up to 17 DIM; Morin et al., 2018), and, finally, disease diagnosis around 30 DIM. That long period between treatment and disease event could have decreased our ability to detect positive effects of the treatment due to the presence of other important disease determinants occurring in the course of those weeks. The same reasoning applies for clinical mastitis up to 90 DIM.

Accurate measurements are necessary to assess the relationship between exposures and outcomes. Errors in measurement are generally divided into random error, or variance, and systematic error, also known as bias. Systematic error, however, is often downplayed, even in very large data sets where it can greatly surpass random error (Lash et al., 2009a). We believe, however, that it is important to quantify systematic error too, and therefore we adjusted the odds ratios obtained with our models for the misclassification bias. In general, the real effect of incomplete milking was higher than the one reported without corrections (i.e., for IMI elimination). However, it was not possible to compute an adjusted odds ratio for all outcomes of interest. Another method that could have been used to control for misclassification bias is the use of Bayesian latent class models, which would allow us to obtain not only an adjusted odds ratio but also an adjusted $95 \%$ confidence interval for the odds ratio (McInturff et al., 2004). In 
the current study we tried using the latter approach, but we had to change to a simpler methodology due to convergence issues with the Bayesian latent class model approach. Our results suggest that incomplete milking during the first 5 DIM increases the odds of IMI elimination but does not affect development of new IMI, clinical mastitis incidence, or reproductive tract health.

\section{ACKNOWLEDGMENTS}

The authors acknowledge the financial support of SD from Novalait, Fonds de recherche du Québec-Nature et technologies (FRQNT, Québec, QC, Canada) and by the Natural Sciences and Engineering Research Council of Canada (Ottawa, ON, Canada) Discovery Grant program. CK was supported by a Natural Sciences and Engineering Research Council of Canada-Collaborative Research and Training Experience in milk quality scholarship. The authors also gratefully acknowledge the participating farmers as well as Caroline Bergeron, Roxanne Mandeville, and Jean-Philippe Pelletier (Université de Montréal, St-Hyacinthe, QC, Canada) for their technical support.

\section{REFERENCES}

Bertoni, G., E. Trevisi, and R. Lombardelli. 2009. Some new aspects of nutrition, health conditions and fertility of intensively reared dairy cows. Ital. J. Anim. Sci. 8:491-518.

Branscum, A. J., I. A. Gardner, and W. O. Johnson. 2005. Estimation of diagnostic-test sensitivity and specificity through Bayesian modeling. Prev. Vet. Med. 68:145-163.

Carbonneau, E., A. M. de Passillé, J. Rushen, B. G. Talbot, and P. Lacasse. 2012. The effect of incomplete milking or nursing on milk production, blood metabolites, and immune functions of dairy cows. J. Dairy Sci. 95:6503-6512.

Cheong, S. H., D. Nydam, K. Galvao, B. Crosier, A. Ricci, L. Caixeta, R. Sper, M. Fraga, and R. Gilbert. 2012. Use of reagent test strips for diagnosis of endometritis in dairy cows. Theriogenology $77: 858-864$.

Clarke, T., E. Cuthbertson, R. Greenall, M. Hannah, and D. Shoesmith. 2008. Incomplete milking has no detectable effect on somatic cell count but increased cell count appears to increase strip yield. Aust. J. Exp. Agric. 48:1161-1167.

Couto, G. B., D. Vaillancourt, and R. Lefebvre. 2013. Comparison of a leukocyte esterase test with endometrial cytology for diagnosis of subclinical endometritis in postpartum dairy cows. Theriogenology 79:103-107.

Denis-Robichaud, J. 2013. Effet d'un traitement intra-utérin de céphapirine sur les performances en reproduction des vaches laitières. MS Thesis. Department of Clinical Sciences, University of Montréal, St-Hyacinthe, Canada.

Denis-Robichaud, J., and J. Dubuc. 2015. Determination of optimal diagnostic criteria for purulent vaginal discharge and cytological endometritis in dairy cows. J. Dairy Sci. 98:6848-6855.

Dohoo, I. R. 2014. Bias - Is it a problem, and what should we do? Prev. Vet. Med. 113:331-337.

Dohoo, I. R., and K. E. Leslie. 1991. Evaluation of changes in somatic cell counts as indicators of new intramammary infections. Prev. Vet. Med. 10:225-237.

Dohoo, I. R., S. W. Martin, and H. Stryhn. 2009. Veterinary Epidemiologic Research. 2nd ed. AVC-Inc., Charlottetown, PEI, Canada.
Drackley, J. K., T. R. Overton, and G. N. Douglas. 2001. Adaptations of glucose and long-chain fatty acid metabolism in liver of dairy cows during the periparturient period. J. Dairy Sci. 84:E100-E112.

Dubuc, J., T. F. Duffield, K. E. Leslie, J. S. Walton, and S. J. LeBlanc. 2010a. Definitions and diagnosis of postpartum endometritis in dairy cows. J. Dairy Sci. 93:5225-5233.

Dubuc, J., T. F. Duffield, K. E. Leslie, J. S. Walton, and S. J. LeBlanc. 2010b. Risk factors for postpartum uterine diseases in dairy cows. J. Dairy Sci. 93:5764-5771.

Dufour, S., I. Dohoo, H. Barkema, L. DesCôteaux, T. DeVries, K. Reyher, J.-P. Roy, and D. Scholl. 2012. Epidemiology of coagulasenegative staphylococci intramammary infection in dairy cattle and the effect of bacteriological culture misclassification. J. Dairy Sci. 95:3110-3124.

Dufour, S., and I. R. Dohoo. 2013. Short communication: Relationship between herd intramammary infection incidence and elimination rate during the dry period. J. Dairy Sci. 96:1672-1676.

Hammon, D. S., I. Evjen, T. Dhiman, J. Goff, and J. Walters. 2006 Neutrophil function and energy status in Holstein cows with uterine health disorders. Vet. Immunol. Immunopathol. 113:21-29.

Hegardt, F. G. 1999. Mitochondrial 3-hydroxy-3-methylglutaryl-CoA synthase: A control enzyme in ketogenesis. Biochem. J. 338:569582.

Holtenius, K., K. Persson Waller, B. Essen-Gustavsson, P. Holtenius, and C. Hallén Sandgren. 2004. Metabolic parameters and blood leukocyte profiles in cows from herds with high or low mastitis incidence. Vet. J. 168:65-73.

Hultén, C. 2016. The effect of different cluster take-off levels at udder quarter in combination with feeding during milking on milk production in dairy cows-Milk yield, milk composition and milking time. MS Thesis. Department of Animal Nutrition and Management, Swedish University of Agricultural Sciences, Uppsala, Sweden.

Huzzey, J. M., D. Veira, D. Weary, and M. Von Keyserlingk. 2007. Prepartum behavior and dry matter intake identify dairy cows at risk for metritis. J. Dairy Sci. 90:3220-3233.

Jago, J. G., J. Burke, and J. Williamson. 2010. Effect of automatic cluster remover settings on production, udder health, and milking duration. J. Dairy Sci. 93:2541-2549.

Kasimanickam, R., T. Duffield, R. Foster, C. Gartley, K. Leslie, J. Walton, and W. Johnson. 2004. Endometrial cytology and ultrasonography for the detection of subclinical endometritis in postpartum dairy cows. Theriogenology 62:9-23.

Kaufmann, T. B. 2010. Clinical and subclinical endometritis in dairy cattle: Prevalence, indicators, and therapy. PhD Thesis. Department of Veterinary Medicine, Freie Universität Berlin, Berlin, Germany.

Krug, C., P. A. Morin, P. Lacasse, D. E. Santschi, J. P. Roy, J. Dubuc, and S. Dufour. 2018. A randomized controlled trial on the effect of incomplete milking during the first 5 days in milk on culling hazard and on milk production and composition of dairy cows. J. Dairy Sci. 101:4367-4377.

Lacetera, N., D. Scalia, U. Bernabucci, B. Ronchi, D. Pirazzi, and A. Nardone. 2005. Lymphocyte functions in overconditioned cows around parturition. J. Dairy Sci. 88:2010-2016.

Lash, T. L., M. P. Fox, and A. K. Fink. 2009a. Applying Quantitative Bias Analysis to Epidemiologic Data. Springer Science and Business Media, Berlin, Germany.

Lash, T. L., M. P. Fox, and A. K. Fink. 2009b. Applying quantitative bias analysis to epidemiologic data. Accessed Feb. 28, 2018. http://sites.google.com/site/biasanalysis.

LeBlanc, S. J., T. Duffield, K. Leslie, K. Bateman, G. P. Keefe, J. Walton, and W. Johnson. 2002. Defining and diagnosing postpartum clinical endometritis and its impact on reproductive performance in dairy cows. J. Dairy Sci. 85:2223-2236.

McDougall, S., R. Macaulay, and C. Compton. 2007. Association between endometritis diagnosis using a novel intravaginal device and reproductive performance in dairy cattle. Anim. Reprod. Sci. 99:9-23. 
McInturff, P., W. O. Johnson, D. Cowling, and I. A. Gardner. 2004 Modelling risk when binary outcomes are subject to error. Stat. Med. 23:1095-1109.

Morin, P. A., C. Krug, Y. Chorfi, J. Dubuc, P. Lacasse, J. P. Roy, D. E. Santschi, and S. Dufour. 2018. A randomized controlled trial on the effect of incomplete milking during early lactation on ketonemia and body condition loss in Holstein dairy cows. J. Dairy Sci. 101:4513-4526.

Mulligan, F. J., and M. L. Doherty. 2008. Production diseases of the transition cow. Vet. J. 176:3-9.

Penry, J. F., E. Endres, B. de Bruijn, A. Kleinhans, P. Crump, D. Reinemann, and L. Hernandez. 2017. Effect of incomplete milking on milk production rate and composition with 2 daily milkings. J. Dairy Sci. 100:1535-1540.

Rasmussen, M. D. 1993. Influence of switch level of automatic cluster removers on milking performance and udder health. J. Dairy Res. 60:287-297.

Reist, M., D. K. Erdin, D. von Euw, K. M. Tschümperlin, H. Leuenberger, H. M. Hammon, N. Künzi, and J. W. Blum. 2003. Use of threshold serum and milk ketone concentrations to identify risk for ketosis and endometritis in high-yielding dairy cows. Am. J. Vet. Res. 64:188-194.

Reyher, K. K., S. Dufour, H. W. Barkema, L. Des Coteaux, T. J. Devries, I. R. Dohoo, G. P. Keefe, J. P. Roy, and D. T. Scholl. 2011. The National Cohort of Dairy Farms - A data collection platform for mastitis research in Canada. J. Dairy Sci. 94:1616-1626.
Schepers, A. J., T. J. G. M. Lam, Y. H. Schukken, J. B. M. Wilmink, and W. J. A. Hanekamp. 1997. Estimation of variance components for somatic cell counts to determine thresholds for uninfected quarters. J. Dairy Sci. 80:1833-1840.

Sheldon, I. M., G. S. Lewis, S. LeBlanc, and R. O. Gilbert. 2006 Defining postpartum uterine disease in cattle. Theriogenology $65: 1516-1530$.

Ster, C., M.-C. Loiselle, and P. Lacasse. 2012. Effect of postcalving serum nonesterified fatty acids concentration on the functionality of bovine immune cells. J. Dairy Sci. 95:708-717.

Stevenson, M., T. Nunes, J. Sanchez, R. Thornton, J. Reiczigel, J. Robison-Cox, and P. Sebastiani. 2012. epiR: An R Package for the Analysis of Epidemiological Data. R package version 0.9-43. Accessed Jul. 23, 2018. https://rdrr.io/cran/epiR/.

Suriyasathaporn, W., C. Heuer, E. N. Noordhuizen-Stassen, and Y. H. Schukken. 2000. Hyperketonemia and the impairment of udder defense: A review. Vet. Res. 31:397-412.

R Core Team. 2013. R: A language and Environment for Statistical Computing. R Foundation for Statistical Computing, Vienna, Austria.

Wathes, D. C., Z. Cheng, N. Bourne, V. J. Taylor, M. P. Coffey, and S. Brotherstone. 2007. Differences between primiparous and multiparous dairy cows in the inter-relationships between metabolic traits, milk yield and body condition score in the periparturient period. Domest. Anim. Endocrinol. 33:203-225. 